\title{
Economic well-being and poverty among the elderly: an analysis based on a collective consumption model*
}

\author{
Laurens Cherchye ${ }^{\dagger}$ Bram De Rock ${ }^{\ddagger}$ and Frederic Vermeulen ${ }^{\S}$
}

February, 2008

\begin{abstract}
We apply the collective consumption model of Browning, Chiappori and Lewbel (2006) to analyse economic well-being and poverty among the elderly. The model focuses on individual preferences, a consumption technology that captures the economies of scale of living in a couple, and a sharing rule that governs the intra-household allocation of resources. The model is applied to a time series of Dutch consumption expenditure surveys. Our empirical results indicate substantial economies of scale and a wife's share that is increasing in total expenditures. We further calculated poverty rates by means of the collective consumption model. Collective poverty rates of widows and widowers turn out to be slightly lower than traditional ones based on a standard equivalence scale. Poverty among women (men) in elderly couples, however, seems to be heavily underestimated (overestimated) by the traditional approach. Finally, we analysed the impact of becoming a widow(er). Based on cross-sectional evidence, we find that the drop (increase) in material well-being following the husband's death is substantial for women in high (low) expenditure couples. For men, the picture is reversed.
\end{abstract}

${ }^{*}$ We are grateful to Lans Bovenberg, Katie Carman, André Decoster, Erwin Ooghe, Jeroen Sabbe, Erik Schokkaert, Ernst van Koesveld, Arthur van Soest, Daniel van Vuuren and Guglielmo Weber for helpful comments. We also thank seminar and conference participants in The Hague, Leuven, Tilburg and Utrecht for useful discussions. In this research, data have been used from the Dutch Consumption Expenditure Survey (1978-2004) of the Central Bureau of Statistics, which have been made available through the Scientific Statistical Agency (WSA).

${ }^{\dagger}$ Center for Economic Studies and Campus Kortrijk, University of Leuven; Fund for Scientific Research - Flanders (FWO-Vlaanderen). E. Sabbelaan 53, B-8500 Kortrijk, Belgium. E-mail: laurens.cherchye@kuleuven-kortrijk.be.

${ }^{\ddagger}$ ECARES and ECORE, Université Libre de Bruxelles. Avenue F. D. Roosevelt 50, 1050 Brussels, Belgium. E-mail: bderock@ulb.ac.be.

${ }^{\S}$ CentER, Department of Econometrics and OR, Tilburg University, Netspar and IZA. P.O. Box 90153, NL-5000 LE Tilburg, The Netherlands. E-mail: frederic.vermeulen@uvt.nl. Frederic Vermeulen gratefully acknowledges financial support from the Netherlands Organisation for Scientific Research (NWO) through a VIDI grant. 
Key words: collective model, intra-household allocation, indifference scales, economies of scale, poverty.

JEL-classification: D11, D12, D13, D63, I31. 


\section{Introduction}

A major concern in light of an ageing population is poverty among widows and widowers and, more generally, the economic well-being of the elderly. As Hurd (1990) rightfully remarks, the issue of poverty is especially troublesome for the elderly since they have fewer possibilities to recover from a drop in income. Compared with prime age individuals, for example, elderly people face more difficulties to (re)enter the labour market. Moreover, given the fall in income after retirement and a lower life expectancy, it is more difficult to overcome unexpected negative income shocks. This lack of ways to get back on track implies that poverty among the elderly tends to be more permanent than for other groups in society.

Numerous studies analysed poverty among the elderly (see Engelhardt and Gruber, 2004, Weir, Willis and Sevak, 2004, McGarry and Schoeni, 2005, and Zaidi et al., 2006, for only a few recent examples). Most of these studies make use of income or expenditure data at the household level to count the number of individuals in poverty. As Deaton and Paxson (1998) indicate, this transition from households to individuals requires assumptions about the intra-household allocation of resources, about differences in needs and about the importance of economies of scale. Most of the analyses of elderly poverty ignore the issue of the intra-household distribution of resources by assuming that all individuals in a household are equally well off. The literature on intra-household allocation, though, convincingly demonstrated that resources are not equally shared within households (see, for example, Browning, Bourguignon, Chiappori and Lechene, 1994, Lundberg, Pollak and Wales, 1997, and other references in Vermeulen, 2002). Further, incomes or expenditures of individuals from different households are usually made comparable to each other by using some equivalence scale (see, for example, Coder, Rainwater and Smeeding, 1989, Slesnick, 1993, Smeeding and Sullivan, 1998, Johnson and Smeeding, 2000, Engelhardt and Gruber, 2004, and Zaidi et al., 2006). Traditional equivalence scales, however, are subject to at least two important criticisms (see Lewbel and Pendakur, 2006, for a survey). Firstly, data on consumption patterns under different price and income regimes can identify the shape and the ranking of indifference curves, but not the utility level attached to each of these curves. Consequently, it is impossible to determine at which level of income or expenditures households with a different demographic composition are equally well off. Secondly, traditional equivalence scales are based on the so-called unitary model, which assumes that a household acts as if it were a single rational decision maker. However, as Browning, Chiappori and Lewbel (2006) stress, it are individuals who have preferences, and not households. As a consequence, the unitary assumption in the analysis of consumer behaviour seems overly restrictive. This argument is supported by the growing empirical evidence that the standard unitary model indeed does not provide an adequate description of observed multi-person household behaviour (see, for example, Fortin and Lacroix, 1997, 
Browning and Chiappori, 1998, and Cherchye and Vermeulen, 2006).

A growingly popular framework for analysing household behaviour is Chiappori's (1988, 1992) collective model. Apart from the starting point that a household consists of individuals with own rational preferences, the collective approach uses the mere assumption that intra-household allocations are Pareto-efficient. Contrary to the unitary model, the collective model entails empirical restrictions that seem more difficult to reject when tested on multi-person household data (see, again, Fortin and Lacroix, 1997, Browning and Chiappori, 1998, and Cherchye and Vermeulen, 2006). In addition, the collective model is particularly useful for addressing welfare-related questions that specifically focus on the within-household distribution of resources (see Chiappori, 1992, and Blundell, Chiappori and Meghir, 2005). Therefore, the collective model seems an obvious point of departure to analyse elderly poverty.

In this paper, we analyse economic well-being and poverty among the elderly by means of Browning, Chiappori and Lewbel's (2006) collective consumption model. They propose a model that is defined in terms of individual preferences, a consumption technology that captures the economies of scale of living in a couple and a sharing rule that governs the intra-household allocation of resources. By combining data from singles and couples via the assumption that preferences over goods do not change when individuals form a couple, they are able to completely identify the model and use it as a basis to calculate economies of scale and so-called indifference scales. ${ }^{1}$ Unlike traditional equivalence scales, these indifference scales do not require any interpersonal utility comparisons. Since they also rest on a structural model that explicitly takes account of individual preferences, indifference scales are not subject to the criticisms on traditional equivalence scales.

We will apply the collective model of Browning, Chiappori and Lewbel (2006) to a time series of consumption expenditure surveys describing the consumption pattern of Dutch elderly couples between 1978 and 2004. As already indicated, we also need singles (whose consumption behaviour can be described by a unitary model) to completely identify the collective consumption model. Therefore, we will also make use of (elderly) widows and widowers that are drawn from the same data source. Worthy of note is that the equal preferences assumption in this context seems less restrictive than when comparing unmarried singles with individuals in couples.

Due to its particular set-up, the collective consumption model of Browning, Chiappori and Lewbel (2006) is able to analyse poverty among the elderly while taking into account the potentially unequal distribution of resources within elderly couples, which is completely ignored in traditional poverty analyses. As we will demonstrate, this analysis yields poverty rates that differ markedly from those obtained by means of a traditional analysis. We will also have a closer look at the economic consequences

\footnotetext{
${ }^{1}$ Other identification strategies are possible if goods are assignable (quod non in our data).
} 
of becoming a widow(er), which is an important policy issue (see Holden, Burkhauser and Feaster, 1988, Weir, Willis and Sevak, 2004, and McGarry and Schoeni, 2005). A very useful concept in this respect is the above mentioned indifference scale that allows comparing the well-being of the same individual in two different living arrangements ( $i n$ casu as a member of a couple and as a widow(er)). Once again, the collective approach is able to shed new light on the issue.

The rest of this paper is structured as follows. In Section 2, we present the respective models that will be used to describe the consumption behaviour of elderly couples and widow(er)s. The empirical specification, data and estimation results are discussed in Section 3. Section 4 focuses on the analysis of the economic well-being and poverty among the elderly by means of the collective consumption model. Section 5 concludes.

\section{The model}

\subsection{Widows and widowers}

Let us start with the (standard) consumption model of a single-person household $k$, where $k=f$ if the household consists of a widow, while $k=m$ if the single is a widower. In what follows, we focus on individuals who do not participate to the labour market (any more). Under the market prices $\mathbf{p}$ and total expenditures $x^{k}$, the individual purchases the $n$-vector of goods $\mathbf{q}^{k}$. Preferences are represented by a twice continuously differentiable, strictly increasing and strictly quasi-concave direct utility function $u^{k}\left(\mathbf{q}^{k}\right)$. A single person $k$ is faced with the following optimization programme:

$$
\max _{\mathbf{q}^{k}} u^{k}\left(\mathbf{q}^{k}\right) \text { subject to } \mathbf{p}^{\prime} \mathbf{q}^{k}=x^{k} .
$$

The maximization problem results in a set of $n$ Marshallian demand equations:

$$
\mathbf{q}^{k}=\mathbf{g}^{k}\left(\mathbf{p} / x^{k}\right),
$$

which satisfy the well-known properties of adding-up, homogeneity, symmetry and negative semidefiniteness of the Slutsky matrix. Substituting these demand equations in the direct utility function obtains the individual's indirect utility function $v^{k}\left(\mathbf{p} / x^{k}\right)$.

\subsection{Elderly couples}

We now consider an elderly two-person $(f$ and $m$ ) household where both individuals do not participate to the labour market (any more). ${ }^{2}$ Contrary to the unitary model for describing household behaviour, the collective model explicitly recognizes that each

\footnotetext{
${ }^{2}$ For simplicity, we will frequently make use of words like "marriage" and "spouse", but, of course, the household members need not necessarily be married.
} 
of the household members has own rational preferences. In what follows, we will assume that individual utility functions are egoistic, in the sense that they only depend on the own consumption bundle. Although there is no doubt that this assumption is more restrictive than when one allows for externalities within the household, it is less restrictive than Chiappori's (1988) egoistic preferences, since, following Browning, Chiappori and Lewbel (2006), we will make use of a consumption technology that accounts for economies of scale in the household. These economies of scale entail gains from marriage, which give individuals a potentially strong economic incentive to form a couple.

Each individual's preferences are represented by a twice continuously differentiable, strictly increasing and strictly quasi-concave direct utility function $u^{k}\left(\mathbf{q}^{k}\right)$. A core feature of the collective model is that it explicitly recognizes that a household that consists of several household members does not necessarily behave as a single decision maker. In other words, the model that is useful to describe widow(er)s' consumption behaviour is no longer useful for couples. Following Chiappori (1988), we will assume that spouses choose Pareto efficient consumption allocations. Without loss of generality, this implies that a couple's objective function can be written as a weighted sum of individual utilities:

$$
\mu(\mathbf{p} / x, \mathbf{s}) u^{f}\left(\mathbf{q}^{f}\right)+u^{m}\left(\mathbf{q}^{m}\right) .
$$

The (positive) Pareto weight $\mu$ represents the female's relative bargaining power and generally depends on prices $\mathbf{p}$ and the couple's total expenditures $x$. (The use of normalized prices implies that we assume that the Pareto weight is not affected by the unit in which monetary variables are expressed). The Pareto weight may further depend on a vector of so-called distribution factors s. These are defined as variables that do not directly affect preferences, nor the budget constraint and consumption technology, but have an impact on spouses' bargaining positions (see, for example, Bourguignon, Browning and Chiappori, 2006). If $\mu$ is increasing in, say, a distribution factor $s$, then the wife's bargaining position improves following an increase in $s$. This implies that she will be able to claim a higher utility than before, which is produced by an intrahousehold allocation that is more favourable to her. More specifically, this is obtained by a greater quantity of the wife's consumption $\mathbf{q}^{f}$ relative to that of the husband. The fact that the household's objective function depends on prices and total expenditures, which implies that Marshallian demand fails to satisfy the usual Slutsky conditions, is the distinguishing characteristic of the collective model as compared to the traditional unitary model.

Like Browning, Chiappori and Lewbel (2006), we will explicitly consider economies of scale of living in a couple. These economies of scale are due to sharing and joint consumption inside the household. Consequently, aggregate individual consumption $\mathbf{q}=\mathbf{q}^{f}+\mathbf{q}^{m}$ will typically not add up to the household's purchased consumption bundle 
z. Examples of goods that may have a public nature are rent or heating: consumption of it by one of the spouses does not reduce the supply available for the other spouse, while no individual can be excluded from consuming it (at least if one does not want to break up the marriage). On the other hand, goods like beverages are purely private: every bottle of coke drunk by one of the members cannot be drunk by the other one. However, in reality, the distinction is not necessarily that easy. When one of the spouses spends most of the day outside the house while the other spouse mainly stays inside, expenditures on heating during the day are private. As the example makes clear, many goods will have both a private and a public component. ${ }^{3}$

Following Browning, Chiappori and Lewbel (2006), we assume that a couple is characterized by a consumption technology that transforms the household's purchased quantity vector $\mathbf{z}$ into two individual vectors of private good equivalents $\mathbf{q}^{f}$ and $\mathbf{q}^{m}$. For simplicity, we will restrict attention to a simple Barten-type linear consumption technology:

$$
\mathbf{z}=\mathbf{A q}
$$

where the technology matrix $\mathbf{A}$ is a diagonal $n$ by $n$ matrix, with entries that are between 0.5 and 1 . Diagonal elements associated with purely private goods are equal to 1, while entries associated with purely public goods are equal to 0.5. Remark, however, that purely public goods also imply that $\mathbf{q}^{f}=\mathbf{q}^{m}$, which is not imposed here. Goods that have both a public and a private component are associated with an entry that is between 0.5 and 1. As discussed by Browning, Chiappori and Lewbel (2006), the above consumption technology is similar to Becker's (1965) household production model. The crucial difference is that the goods purchased at the market serve as inputs to produce a greater quantity of the same goods via sharing, and thus are not inputs to produce household goods as in a Beckerian model.

Given all this, we can formulate the couple's optimization programme. This programme boils down to the assumption that spouses maximize a weighted sum of utilities subject to the consumption technology and the household's budget constraint:

$$
\max _{\mathbf{q}^{f}, \mathbf{q}^{m}, \mathbf{z}} \mu(\mathbf{p} / x, \mathbf{s}) u^{f}\left(\mathbf{q}^{f}\right)+u^{m}\left(\mathbf{q}^{m}\right)
$$

subject to

$$
\mathbf{z}=\mathbf{A q} \text { and } \mathbf{p}^{\prime} \mathbf{z}=x .
$$

The optimization programme results in a set of $n$ household demand functions and two

\footnotetext{
${ }^{3}$ See Browning and Chiappori (1998) and Cherchye, De Rock and Vermeulen (2007) for collective consumption models that explicitly account for different uses (private, public or both) of the purchased consumption bundle.
} 
sets of $n$ private good equivalent demand functions:

$$
\begin{aligned}
\mathbf{z} & =\mathbf{g}(\mathbf{p} / x) \\
\mathbf{q}^{f} & =\mathbf{h}^{f}(\mathbf{p} / x) \\
\mathbf{q}^{m} & =\mathbf{h}^{m}(\mathbf{p} / x) .
\end{aligned}
$$

Remark that contrary to the household's demand $\mathbf{z}$, private good equivalent consumption $\mathbf{q}^{f}$ and $\mathbf{q}^{m}$ is generally unobserved.

Browning, Chiappori and Lewbel (2006) also derived a dual representation of the household's optimization programme. This dual representation boils down to a twostage budgeting process. In a first stage, household members divide the household's aggregate resources among each other. In the second stage, each individual maximizes her/his own utility subject to the resulting shares and taking account of personalized prices. In a collective model with only private consumption, these personalized prices are equal to observed market prices. In a context with public consumption, this is no longer the case: personalized prices are a vector of Lindahl prices such that, at these prices and the individual's fraction of the household's aggregate resources, each individual is willing to consume her/his vector of private good equivalents.

More precisely, using the results of Browning, Chiappori and Lewbel (2006), it can be shown that, under the above stated assumptions on individual preferences, the household's budget constraint and the consumption technology, there exists a Lindahl type vector of personalized prices

$$
\boldsymbol{\pi}(\mathbf{p} / x)=\frac{\mathbf{A}^{\prime} \mathbf{p}}{x}
$$

and a sharing rule $\eta(\mathbf{p} / x, \mathbf{s})$, constrained between 0 and 1 , such that:

$$
\begin{aligned}
\mathbf{q}^{f} & =\mathbf{h}^{f}(\mathbf{p} / x)=\mathbf{g}^{f}\left(\frac{\boldsymbol{\pi}(\mathbf{p} / x)}{\eta(\mathbf{p} / x, \mathbf{s})}\right) \\
\mathbf{q}^{m} & =\mathbf{h}^{m}(\mathbf{p} / x)=\mathbf{g}^{m}\left(\frac{\boldsymbol{\pi}(\mathbf{p} / x)}{1-\eta(\mathbf{p} / x, \mathbf{s})}\right) \\
\mathbf{z} & =\mathbf{g}(\mathbf{p} / x)=\mathbf{A g}^{f}\left(\frac{\boldsymbol{\pi}(\mathbf{p} / x)}{\eta(\mathbf{p} / x, \mathbf{s})}\right)+\mathbf{A g}^{m}\left(\frac{\boldsymbol{\pi}(\mathbf{p} / x)}{1-\eta(\mathbf{p} / x, \mathbf{s})}\right) .
\end{aligned}
$$

The Lindahl type vector of personalized prices are normalized such that the household's aggregate resources are equal to $\boldsymbol{\pi}^{\prime}\left(\mathbf{q}^{f}+\mathbf{q}^{m}\right)=1$, whereas the shares $\eta$ and $(1-\eta)$ of the household's resources that are allocated to the wife and to the husband are respectively equal to $\boldsymbol{\pi}^{\prime} \mathbf{q}^{f}$ and $\boldsymbol{\pi}^{\prime} \mathbf{q}^{m}$. Similar to the Pareto weight $\mu$, the sharing rule $\eta$ is a measure of the wife's weight in the household's decision making process. Ceteris paribus, the higher the share $\eta$, the higher the utility that will be attained by the wife 
by means of a higher private consumption $\mathbf{q}^{f}$. In contrast with the Pareto weight $\mu$, the sharing rule $\eta$ does not depend on the particular cardinalization chosen to represent individual preferences.

A core question now is whether the above collective model can be identified given observable couple's demand functions $\mathbf{g}(\mathbf{p} / x)$ and widow(er)s' demand functions $\mathbf{g}^{f}(\mathbf{p} / x)$ and $\mathbf{g}^{m}(\mathbf{p} / x)$. In other words, can we identify the sharing rule $\eta(\mathbf{p} / x, \mathbf{s})$, the consumption technology $\mathbf{A}$, personalized prices $\boldsymbol{\pi}(\mathbf{p} / x)$ and individual private good equivalents $\mathbf{h}^{f}(\mathbf{p} / x)$ and $\mathbf{h}^{m}(\mathbf{p} / x)$ given observed demand? Browning, Chiappori and Lewbel (2006) demonstrated that a sufficient condition is implied by the assumption that preferences of individuals do not change when they form a couple. In our application, this can be rephrased as individual preferences staying the same after becoming a widow(er).

The intuition of the identification result is as follows. The couples' demand functions $\mathbf{g}(\mathbf{p} / x)$ can be easily identified if one observes ordinary demand data with observed prices $\mathbf{p}$, total expenditures $x$ and consumption bundles z. Similarly, the above equal preferences assumption allows us to identify individual demand functions $\mathbf{g}^{f}(\mathbf{p} / x)$ and $\mathbf{g}^{m}(\mathbf{p} / x)$ using ordinary demand data for respectively widows and widowers. It is wellknown in consumer theory that one can identify (up to a monotone increasing transformation) the widows' and widowers' indirect utility functions $v^{f}$ and $v^{m}$ by means of the identified individual demand functions $\mathbf{g}^{f}(\mathbf{p} / x)$ and $\mathbf{g}^{m}(\mathbf{p} / x)$. Finally, the remaining components of the collective consumption model $\mathbf{A}, \boldsymbol{\pi}(\mathbf{p} / x), \eta(\mathbf{p} / x, \mathbf{s}), \mathbf{h}^{f}(\mathbf{p} / x)$ and $\mathbf{h}^{m}(\mathbf{p} / x)$ can be identified by making use of the identified individual demand functions $\mathbf{g}^{f}(\mathbf{p} / x)$ and $\mathbf{g}^{m}(\mathbf{p} / x)$ and observable elderly couples' demand functions $\mathbf{g}(\mathbf{p} / x)$.

\subsection{Welfare-analytical concepts}

Once the above collective consumption model is identified, two useful welfare-analytical concepts can be derived (see also Lewbel, 2003a, 2003b). A first concept is a measure for the economies of scale of living in a couple. Following Browning, Chiappori and Lewbel (2006), this measure can be defined as follows:

$$
e=\frac{\mathbf{p}^{\prime}\left(\mathbf{q}^{f}+\mathbf{q}^{m}\right)}{\mathbf{p}^{\prime} \mathbf{z}}-1 .
$$

The measure compares the expenditures that would be needed to finance aggregate private consumption $\mathbf{q}=\mathbf{q}^{f}+\mathbf{q}^{m}$ when both individuals would be living alone rather than in a couple with the expenditures that are needed to purchase the consumption bundle $\mathbf{z}$. It is clear that the more sharing inside the household, the higher the economies of scale will be. Two extreme cases can be distinguished. Firstly, if all consumption would be purely private, then aggregate private consumption q would be equal to the observed couple's consumption bundle $\mathbf{z}$ (see the consumption technology function in (2.4)). In that case, the measure for the economies of scale $e$ would be equal to zero and 
would reach its minimum. Secondly, if all consumption would be purely public, then aggregate private consumption would be equal to two times the couple's consumption bundle $\mathbf{z}$. In this case, the measure for the economies of scale $e$ would be equal to 1 and would reach its maximum. It should be stressed that the measure for the economies of scale assumes that there is no shift in the individual consumption pattern when both spouses would live alone rather than in a couple. As soon as individuals live alone, they are confronted with market prices instead of the individual shadow prices. As soon as both sets of prices do not coincide (as expected), the optimal consumption pattern can be different.

Lewbel (2003a, 2003b) and Browning, Chiappori and Lewbel (2006) suggest so-called indifference scales to account for possible shifts in the individual budget allocation. The indifference scales for women and men are respectively defined as:

$$
\begin{aligned}
s^{f} & =\frac{\min _{\mathbf{q}^{f *}}\left(\mathbf{p}^{\prime} \mathbf{q}^{f *} \mid u^{f}\left(\mathbf{q}^{f *}\right)=u^{f}\left(\mathbf{q}^{f}\right)\right)}{x} \\
s^{m} & =\frac{\min _{\mathbf{q}^{m *}}\left(\mathbf{p}^{\prime} \mathbf{q}^{m *} \mid u^{m}\left(\mathbf{q}^{m *}\right)=u^{m}\left(\mathbf{q}^{f}\right)\right)}{x} .
\end{aligned}
$$

The numerator of these indifference scales is equal to the minimum expenditures needed for a female or male individual living alone to reach the same indifference curve as when (s)he would live in a couple and obtain a vector of private good equivalents of respectively $\mathbf{q}^{f}$ or $\mathbf{q}^{m}$. The denominator is equal to the couple's total expenditures $x$ that are used to finance household consumption z. Two remarks are in order. Firstly, as discussed by Lewbel (2003a, 2003b) and Browning, Chiappori and Lewbel (2006), these indifference scales do not suffer from the well-known deficiency of standard equivalence scales with respect to interpersonal utility comparisons. As is clear from the above definitions, the utility level of the same individual is compared for two different living arrangements. In other words, the indifference scales are not affected by the particular cardinal representation of the individual preferences and thus do not involve any interpersonal utility comparisons like standard equivalence scales. Of course, the applicability of the above concepts still rests on the assumption that preferences do not change when an individual becomes a widow(er). ${ }^{4}$ A second remark is that the indifference scales will not only depend on individual preferences, but also on the consumption technology and the shares that are allocated to both spouses (see equation (2.8)). If, say, a change in the distribution factor $s$ is such that the share allocated to the wife increases, then she will generally need more expenditures when living alone to reach the same indifference curve as when she is living in a couple after the change in the distribution factor.

\footnotetext{
${ }^{4}$ Note that, since the model is overidentified, there are possibilities to model preference changes when moving between living arrangements (see Browning, Chiappori and Lewbel, 2006).
} 


\section{Empirical application}

\subsection{Empirical specification}

In what follows, we will first discuss the consumption behaviour (individual preferences and observed demand) of widows and widowers. Next, we will focus on the assumptions we make on the consumption technology and the sharing rule applied to elderly couples. Finally, we will discuss how these assumptions are reflected in observed demand behaviour of elderly couples.

\subsubsection{Individuals' preferences}

We assume that widows and widowers' preferences can be represented by the indirect utility function underlying the Quadratic Almost Ideal Demand System (QUAIDS) of Banks, Blundell and Lewbel (1997). As is well-known, QUAIDS allows flexible price responses while preserving theoretical consistency. Moreover, given its quadratic income responses, its Engel curves are able to display a great variety of shapes. The individual indirect utility function is thus assumed to be of the following form $(k=f, m)$ :

$$
v^{k}=\left\{\left[\frac{\ln x^{k}-\ln a^{k}(\mathbf{p})}{b^{k}(\mathbf{p})}\right]^{-1}+\lambda^{k}(\mathbf{p})\right\}^{-1},
$$

where

$$
\begin{aligned}
\ln a^{k}(\mathbf{p}) & =\alpha_{0}^{k}+\sum_{i=1}^{n} \alpha_{i}^{k} \ln p_{i}+\frac{1}{2} \sum_{i=1}^{n} \sum_{j=1}^{n} \gamma_{i j}^{k} \ln p_{i} \ln p_{j} \\
b^{k}(\mathbf{p}) & =\prod_{i=1}^{n} p_{i}^{\beta_{i}^{k}} \\
\lambda^{k}(\mathbf{p}) & =\sum_{i=1}^{n} \lambda_{i}^{k} \ln p_{i} .
\end{aligned}
$$

The parameters $\alpha_{i}^{k}, \beta_{i}^{k}, \lambda_{i}^{k}$ and $\gamma_{i j}^{k}(\forall i, j, k)$ are to be estimated. Following Banks, Blundell and Lewbel (1997), the parameter $\alpha_{0}^{k}$ is chosen to be just below the lowest value of $\ln x^{k}(k=f, m)$ in the data. Adding-up requires that $\sum_{i} \alpha_{i}^{k}=1, \sum_{i} \beta_{i}^{k}=0$, $\sum_{i} \lambda_{i}^{k}=0$ and $\sum_{i} \gamma_{i j}^{k}=0 \forall j$. Homogeneity is satisfied if $\sum_{j} \gamma_{i j}^{k}=0 \forall i$. Slutsky symmetry is satisfied if $\gamma_{i j}=\gamma_{j i} \forall i, j$. Note that the indirect utility function underlying Deaton and Muellbauer's (1980) Almost Ideal Demand System corresponds to equation (3.1) where $\lambda_{i}^{k}=0$ for all goods. Applying Roy's identity to equation (3.1), we obtain the QUAIDS budget share equations for commodity $i(i=1, \ldots, n)$ and individual $k$ 
$(k=f, m):$

$$
w_{i}^{k}=\alpha_{i}^{k}+\sum_{j=1}^{n} \gamma_{i j}^{k} \ln p_{j}+\beta_{i}^{k} \ln \left[\frac{x^{k}}{a^{k}(\mathbf{p})}\right]+\frac{\lambda_{i}^{k}}{b^{k}(\mathbf{p})}\left\{\ln \left[\frac{x^{k}}{a^{k}(\mathbf{p})}\right]\right\}^{2} .
$$

The impact of individual demographic characteristics runs through the coefficients $\alpha_{i}^{k}$ $(\forall i)$, although there are also other possibilities. Given the earlier discussion on the identification issue, we will assume that preferences of widows and widowers are equal to the preferences of respectively female and male individuals in elderly couples. As a

result, the parameters $\alpha_{i}^{k}, \beta_{i}^{k}, \lambda_{i}^{k}$ and $\gamma_{i j}^{k}(\forall i, j, k)$ will be the same across both types of female and male individuals. Of course, real expenditures and prices appearing in the demand equations will differ between widow(er)s and individuals in couples as will be illustrated next.

\subsubsection{Consumption technology}

Let us now turn attention to the structural model components that are associated with elderly couples. As noticed before, we will assume a Barten-type linear consumption technology. Therefore, the link between couples' observed demand of good $i$ (denoted by $z_{i}$ ) and the household members' private good equivalents (denoted by $q_{i}^{f}$ and $q_{i}^{m}$ ) is given by $(i=1, \ldots, n)$ :

$$
z_{i}=A_{i}\left(q_{i}^{f}+q_{i}^{m}\right)
$$

where $A_{i}$ is the corresponding diagonal entry in the technology matrix $\mathbf{A}$ (see equation (2.4)). In the empirical application, we will constrain $A_{i}$ between 0.5 and 1 (which are the benchmark cases of respectively purely public consumption and purely private consumption) by assuming the following functional specification for $A_{i}(i=1, \ldots, n)$ :

$$
A_{i}=\frac{1+\frac{\exp \left(a_{i}\right)}{1+\exp \left(a_{i}\right)}}{2}
$$

where $a_{i}$ is a parameter to be estimated.

\subsubsection{Sharing rule}

In the empirical application, we assume that the sharing rule depends on real expenditures, which imposes some structure on the impact of normalized prices on the sharing rule. Real expenditures are here defined as the difference between the logarithm of total expenditures $x$ and the Stone price index $\sum_{i} w_{i}^{*} \ln p_{i}$, where $w_{i}^{*}$ is the average budget share of commodity $i$ in the couples' data. Next, an obvious distribution factor would be the income share of, say, the female in the household (see, e.g., Browning, Bourguignon, 
Chiappori and Lechene, 1994). However, we do not have this information available in the data that we use. Given this, we use a dummy variable that indicates whether the female has a strictly higher schooling level than the male, as this difference in schooling levels is potentially correlated with the female's income share. Finally, as is clear from the discussion following equation (2.8), the sharing rule is bounded between 0 and 1 . Therefore, we opt for the following functional specification:

$$
\eta=\frac{\exp \left(\delta_{0}+\delta_{1} y+\delta_{2} s\right)}{1+\exp \left(\delta_{0}+\delta_{1} y+\delta_{2} s\right)}
$$

where $y$ denotes real expenditures and $s$ represents a dummy variable that indicates whether the female has a strictly higher schooling level than the male and where $\delta_{i}$ $(i=0,1,2)$ are parameters to be estimated. ${ }^{5}$

\subsubsection{Couples' demand system}

Let us now derive the budget share equations for elderly couples. For individual preferences that can be represented by the QUAIDS model and the Barten-type linear consumption technology, the budget share version of equation (2.8) is of the following form (see also Browning, Chiappori and Lewbel, 2006) $(i=1, \ldots, n)$ :

$$
\begin{aligned}
w_{i}= & \eta\left\{\alpha_{i}^{f}+\sum_{j=1}^{n} \gamma_{i j}^{f} \ln \pi_{j}+\beta_{i}^{f} \ln \left[\frac{\eta}{a^{f}(\boldsymbol{\pi})}\right]+\frac{\lambda_{i}^{f}}{b^{f}(\boldsymbol{\pi})}\left\{\ln \left[\frac{\eta}{a^{f}(\boldsymbol{\pi})}\right]\right\}^{2}\right\} \\
& +(1-\eta)\left\{\alpha_{i}^{m}+\sum_{j=1}^{n} \gamma_{i j}^{m} \ln \pi_{j}+\beta_{i}^{m} \ln \left[\frac{(1-\eta)}{a^{m}(\boldsymbol{\pi})}\right]+\frac{\lambda_{i}^{m}}{b^{m}(\boldsymbol{\pi})}\left\{\ln \left[\frac{(1-\eta)}{a^{m}(\boldsymbol{\pi})}\right]\right\}^{2}\right\} .
\end{aligned}
$$

Interestingly enough, the budget share for commodity $i$ is equal to a weighted average of individual budget shares, with weights equal to the spouses' shares in the (appropriately defined) household's aggregate resources. Moreover, the higher the share of an individual, the more the couple's demand will resemble the demand of this individual when faced with her/his shadow prices and income.

\subsection{Estimation strategy}

It is clear from equations (2.7), (3.4), (3.5) and (3.6) that the system of budget share functions is highly nonlinear in the parameters to be estimated. Moreover, preference

\footnotetext{
${ }^{5}$ We also experimented with a sharing rule that included a time trend to capture potential changes in sociological or cultural attitudes with respect to sharing between spouses. Since this did not affect the analysis in qualitative or quantitative terms, we opted to restrict to the more parsimonious sharing rule in what follows.
} 
parameters of widows and widowers (whose demand behaviour is assumed to be captured by the QUAIDS model of equation (3.2)) are the same of those of respectively female and male spouses in elderly couples. Another issue is that total expenditures may be endogenous. In Browning, Chiappori and Lewbel (2006), the complete system (without constraining technology parameters) is estimated by means of the Generalized Method of Moments (GMM) and by simultaneously making use of couples and female and male singles. Because their procedure is very time consuming and resulted in some convergence difficulties, we opted for a less efficient but computationally simple and consistent estimation strategy.

In the first step of our estimation strategy, we estimated QUAIDS parameters on samples of widows and widowers (see equation (3.2)). Note that this involves both within-equation (homogeneity) and cross-equation restrictions (adding-up and symmetry). Adding-up is automatically satisfied given that budget shares add up to one by definition. Estimation proceeds by leaving out one of the commodities and estimating a reduced demand system consisting of only $n-1$ equations. Homogeneity is imposed via the restriction $\sum_{j} \gamma_{i j}^{k}=0(\forall i)$, which basically implies that relative prices are used in the reduced demand system (that is, observed prices divided by the price of the commodity left out). Specifically, the following systems (one for each sex) are estimated $(i=1, \ldots, n-1)$ :

$$
w_{i}^{k}=\alpha_{i}^{k}+\sum_{j=1}^{n-1} \gamma_{i j}^{k}\left(\ln p_{j}-\ln p_{n}\right)+\beta_{i}^{k} \ln \left[\frac{x^{k}}{a^{k *}(\mathbf{p})}\right]+\frac{\lambda_{i}^{k}}{b^{k *}(\mathbf{p})}\left\{\ln \left[\frac{x^{k}}{a^{k *}(\mathbf{p})}\right]\right\}^{2},
$$

where

$$
\begin{aligned}
\ln a^{k *}(\mathbf{p}) & =\alpha_{0}^{k}+\ln p_{n}+\sum_{i=1}^{n-1} \alpha_{i}^{k}\left(\ln p_{i}-\ln p_{n}\right)+\frac{1}{2} \sum_{i=1}^{n-1} \sum_{j=1}^{n-1} \gamma_{i j}^{k}\left(\ln p_{i}-\ln p_{n}\right)\left(\ln p_{j}-\ln p_{n}\right) \\
b^{k *}(\mathbf{p}) & =\prod_{i=1}^{n-1}\left(\frac{p_{i}}{p_{n}}\right)^{\beta_{i}^{k}} .
\end{aligned}
$$

Homogeneity restricted QUAIDS parameters were obtained by Blundell and Robin's (1999) iterated linear least squares estimator. As mentioned earlier, total expenditures are likely to be endogenous. Blundell and Robin (1999) demonstrated that the iterated linear least squares estimator can be generalized to allow for endogenous regressors by making use of an augmented regression framework. More specifically, in each equation of the reduced demand system, an extra regressor is taken up to control for endogenous total expenditures. This regressor is the estimated residual from a regression of $\ln x^{k}$ on the logarithm of an individual's income, the square of the logarithm of an individual's income and all exogenous variables in the demand system. Standard errors for 
the homogeneity restricted parameters were obtained by a bootstrap procedure. Finally, consistent symmetry restricted QUAIDS estimates were obtained by a minimum distance procedure (see Browning and Meghir, 1991, and Banks, Blundell and Lewbel, 1997). Denote the homogeneity restricted parameters by $\boldsymbol{\theta}^{k}$ and the symmetry restricted parameters by $\phi^{k}(k=f, m)$. Under the null hypothesis of a symmetric Slutsky matrix $\boldsymbol{\theta}^{k}=\mathbf{K} \boldsymbol{\phi}^{k}$, where $\mathbf{K}$ is a matrix that imposes $\gamma_{i j}^{k}=\gamma_{j i}^{k}(\forall i, j)$. Symmetry restricted estimates are obtained by minimizing the function $\left(\widehat{\boldsymbol{\theta}}^{k}-\mathbf{K} \boldsymbol{\phi}^{k}\right)^{\prime} \widehat{\mathbf{V}}^{-1}\left(\widehat{\boldsymbol{\theta}}^{k}-\mathbf{K} \boldsymbol{\phi}^{k}\right)$, where $\widehat{\boldsymbol{\theta}}^{k}$ is the vector of estimated homogeneity restricted parameters and $\widehat{\mathbf{V}}^{-1}$ is the inverse of the variance-covariance matrix of $\widehat{\boldsymbol{\theta}}^{k}$. An estimate for the variance-covariance matrix of the symmetry restricted parameters is $\left(\mathbf{K}^{\prime} \widehat{\mathbf{V}}^{-1} \mathbf{K}\right)^{-1}$.

In the second step of our estimation strategy, consumption technology and sharing rule parameters are obtained by GMM while taking the estimated preference parameters as given. Following Browning, Chiappori and Lewbel (2006), we assume that the demand system residuals are uncorrelated across elderly couples but correlated across goods at the household level. Assume that we have to estimate $P$ consumption technology and sharing rule parameters and that we have $R(\geq P)$ instruments. Denote the $(P \times 1)$-vector of consumption technology and sharing rule parameters by $\varphi$ and the $(R \times 1)$-vector of instruments for couple $h$ by $\mathbf{r}_{h}$. The observed budget share for commodity $i$ of couple $h$ is denoted by $w_{i, h}$, while the corresponding estimated budget share is denoted by $\widehat{w}_{i, h}(\boldsymbol{\varphi})$. The $((n-1) \times 1)$-vector of error terms of couple $h$ is given by $\mathbf{u}_{h}=\left(u_{1, h}, \ldots, u_{n-1, h}\right)^{\prime}$, where $u_{i, h}=w_{i, h}-\widehat{w}_{i, h}(\boldsymbol{\varphi})$. Assuming that we have $H$ elderly couples in the sample, the $(R(n-1) \times 1)$-vector of sample moments is given by:

$$
v(\boldsymbol{\varphi})=\frac{1}{H} \sum_{h=1}^{H}\left[\mathbf{I}_{n-1} \otimes \mathbf{r}_{h}\right] \mathbf{u}_{h} .
$$

The sample equivalent of the optimal weighting matrix equals:

$$
\mathbf{W}_{H}=\left(\frac{1}{H} \sum_{h=1}^{H}\left[\mathbf{I}_{n-1} \otimes \mathbf{r}_{h}\right] \widehat{\mathbf{u}}_{h} \widehat{\mathbf{u}}_{h}^{\prime}\left[\mathbf{I}_{n-1} \otimes \mathbf{r}_{h}\right]^{\prime}\right)^{-1}
$$

where $\widehat{\mathbf{u}}_{h}$ is couple $h$ 's residual obtained by a first stage GMM with a suboptimal weighting matrix that equals an $(R(n-1) \times R(n-1))$ identity matrix. The GMMestimator $\widehat{\varphi}$ minimizes a quadratic form in the sample moments:

$$
\min _{\varphi}\left[v(\varphi)^{\prime} \mathbf{W}_{H} v(\varphi)\right]
$$

Standard errors have been computed by using the bootstrap. 


\subsection{Data}

The data we use is a time-series of cross-sections drawn from the Dutch Consumption Expenditure Survey that is conducted by Statistics Netherlands at an annual basis. We use data from 1978 to 2004. The sample selection is for widows and widowers who are aged $65+$ and for couples with no one else in the household and where each individual is aged $65+$. None of the individuals in the sample participates in the labour market. This results in a sample that consists of 1401 widows, 434 widowers and 3020 couples. We focus on a commodity bundle that consists of 6 non-durable goods: (1) food (including non-alcoholic beverages), (2) vices (alcoholic drinks and tobacco), (3) housing (including rent for tenants, imputed rent for home owners and maintenance), (4) clothing (including shoes), (5) transport (without the purchase of vehicles) and (6) energy (including heating and electricity). We assume that preferences for these goods are separable from all other goods, although we allow for some non-separabilities by conditioning on car ownership and home ownership. An important remark in this respect is that we assume that dummy variables capturing car and home ownership are exogenous. Clearly, more research (of both a theoretical and empirical nature) to analyse this issue is needed in the future. Another potential selection issue is that on being widow(er) or living in a couple. Here we assume that becoming a widow(er) is an exogenous shock to a household, which does not entail a shift in the survivor's preferences. Prices are obtained via Statistics Netherlands. Relative prices are defined with respect to the price associated with energy, which is left out from the reduced demand system. Remark that we only have intertemporal price variation, which, as the application will show, is sufficient though to estimate the model.

Individual demographic characteristics that affect preferences are, apart from the earlier mentioned dummy variables for car and home ownership, the age class, two dummy variables capturing the individual's education level and four dummy variables that capture preference heterogeneity across time. (Since we do not have any crosssection price variation, yearly dummies cannot be included in the model). Instruments used in the second step of our estimation strategy (GMM estimation of consumption technology and sharing rule parameters) are a constant, two dummy variables capturing the education levels of each of the spouses, dummy variables for car and home ownership, four dummy variables indicating the time period of observation, the logarithm of the five relative prices, the logarithm of the absolute price of energy, the logarithm of the couple's real income (defined as the logarithm of nominal income minus the above described Stone price index) and its square, the products of the real income variable with respectively the dummies for car and home ownership and the time dummies, and a dummy that indicates whether the wife has a strictly higher schooling level than the husband. Some summary statistics are provided in Table A1 of the Appendix. 


\subsection{Results}

Let us first discuss the estimation results for the QUAIDS parameters for widows and widowers. For the sake of brevity, we only discuss the expenditure and the uncompensated own price elasticities. (Parameter estimates are given in Tables A2 and A3 of the Appendix). These elasticities are reported in Table 1. They are calculated for the average expenditures and prices in the widows' and widowers' samples. The table shows that expenditure elasticities are relatively precisely estimated, while the own price elasticities are less precise (especially those for widowers). This follows from the relatively little intertemporal price variation. Food, vices and energy are necessities for both widows and widowers, while clothing, housing and transport turn out to be luxuries. Uncompensated own price elasticities are all negative. Interestingly enough, a chi-squared test could not reject symmetry of the Slutsky matrix for both widows and widowers at a 5 per cent significance level: test statistics equal 14.16 and 12.21 respectively, which are lower than the critical value $\chi^{2}(10)=18.31$.

\section{Table 1 about here.}

Let us now focus attention to the GMM estimation results with respect to sharing rule and consumption technology parameters in the model for elderly couples. An overidentifying restrictions test rejects the null hypothesis that moment conditions were correctly specified at the 5 per cent significance level: the test statistic equals 1064.91, while $\chi^{2}(140)=168.61$. However, using the Leamer-Schwarz critical value with a 5 per cent significance level and 140 degrees of freedom (degrees of freedom $\times \ln (H)=1121.82$ ) does not result in a rejection. Given the poor small-sample properties of the GMM estimator and the rather complex nonlinear model that we estimated, this seems to suggest that we can be relatively confident in the model.

Table 2 shows the estimated sharing rule parameters and their standard errors. It demonstrates that, ceteris paribus, higher real expenditures imply a significantly higher share for females. This result, which de facto implies a strong rejection of the unitary model for describing couples' behaviour, is in line with earlier findings in the literature (see Browning, Bourguignon, Chiappori and Lechene, 1994, and Browning, Chiappori and Lewbel, 2006). Further, all else equal, the share that is shifted to the woman is higher when she has a higher education level than her husband. This effect is not significant though. To interpret the results, we also calculated the sharing rule for all couples in the data set. The average share turns out to be equal to 0.49 with a standard deviation of 0.10 , a minimum of 0.21 and a maximum of 0.85 . This implies that the average couple's consumption pattern is equal to about the average of the respective consumption patterns of wives and husbands when they would be faced with their own shadow prices and shadow income (see equation (3.6)). Still, there is quite some heterogeneity across couples with different total expenditures. 
Table 2 about here.

The estimation results with respect to the consumption technology are presented in Table 3. The first two columns of the table show the consumption technology parameters $a_{i}$ and their standard errors, while the last two columns show the implied entries of the diagonal technology matrix $A_{i}$ and the associated standard errors. First of all, it is clear that no consumption technology parameter is constrained to either one half or one. It turns out that food, vices and clothing are close to being purely private goods, while housing and energy are close to the benchmark of purely public goods. Transport is somewhere in between. All in all, these are quite intuitive results that comply with our prior expectations.

A useful device to interpret the couples' estimation results is the measure for the economies of scale of living in a couple (see equation (2.9)). We calculated this measure for all the couples in the sample. The average value for the economies of scale measure equals 0.32 , with a standard deviation of 0.02 , a minimum value of 0.27 and a maximum value of 0.37 . Recall that two benchmark cases can be distinguished: a scale equal to zero would refer to a situation where all consumption is purely private, while a scale equal to one would be associated with a situation where all consumption is purely public. Clearly, the model's estimates suggest that a fairly large part of elderly couples' consumption has a public nature. This is of course not surprising given the estimated consumption technology parameters combined with observed budget shares.

Table 3 about here.

\section{Economic well-being and poverty among the elderly}

In this section we will analyse poverty among elderly people in the Netherlands by means of the above collective consumption model. Where necessary, we compare the results with those obtained by a more traditional analysis that is based on the OECD equivalence scale; this illustrates the impact on key policy indicators of choosing a different approach. As is clear from the above discussion, the difference between both approaches will be mainly driven by the collective model allowing for household members that have different preferences, unequal sharing of resources within couples and for substantial economies of scale of living in a couple. 


\subsection{Traditional and collective poverty rates}

Table 4 shows the evolution of poverty rates for individuals in elderly couples and widow(er)s. ${ }^{6}$ Traditional and collective poverty rates are given. The poverty rate in the traditional approach is calculated in three steps (see, for example, Zaidi et al., 2006). Firstly, equivalent expenditures were calculated by dividing household expenditures by the modified OECD equivalence scale. Since we only focus on widow(er)s and elderly couples with no one else in the household, household expenditures are either divided by 1 (single individuals) or by 1.5 (couples). Remark that this modified OECD scale complies with an economies of scale measure of 0.33 (see equation (2.9)), which is actually very close to the average economies of scale measure for the estimated collective model (which, to recall, equals 0.32). Secondly, the resulting equivalent expenditures of widows, widowers and individuals in elderly couples were merged to obtain the median of the equivalent expenditures. Thirdly, an individual is considered to be poor if her $/$ his equivalent expenditures are lower than 60 per cent of median equivalent expenditures (within the complete sample).

The crucial difference between the traditional approach and our collective approach pertains to the first step of the poverty rate calculation. Rather than using equivalent expenditures, the collective approach first calculates the expenditures on private good equivalent consumption valued at market prices. As discussed earlier, these expenditures depend on the economies of scale associated with living in a couple and on the sharing rule. As such, the expenditures on private good equivalent consumption may differ across spouses. Note that, by definition, the expenditures on private good equivalents equal household (equivalent) expenditures for widow(er)s.

Table 4 reveals useful information. It demonstrates that the poverty rate for female and male individuals in elderly couples and widow(er)s steadily decreased between 1978 and 2004. This is so for both sets of poverty rates. The decrease in poverty among the elderly is consistent with other sources (see Vrooman, Soede, Dirven and Trimp, 2005). In the last time period (1998-2004), it is even the case that only women in couples are at risk of poverty on the basis of the collective poverty measure. The poverty rates in the last time period are lower than the rates usually reported in the literature. According to Zaidi et al. (2006), the proportion of elderly at risk of poverty equals about 7 per cent in the Netherlands, while the EU 25 (15) average equals 18 (19) per cent. Note, however, that the (traditional and collective) poverty rates are not directly comparable to those usually reported: firstly, the median of the (equivalent) expenditures (on private good equivalents) is constructed on a dataset that only consists of widow(er)s and elderly couples; secondly, Zaidi et al. (2006) focus on disposable

\footnotetext{
${ }^{6}$ We focused on five time periods where, for each period, five cross-sections were merged. A focus on yearly poverty rates would be less robust since for some years there is only a small number of widows and/or widowers.
} 
income rather than on expenditures. ${ }^{7}$ Table 4 further shows that the poverty rates of women in couples are substantial and much higher than those of men in couples in the first time periods considered. (Recall that the rates for men and women in couples are by definition equal to each other in the traditional approach). This remarkable result can be explained by the fact that an important part of the household's budget is spent on public consumption and that the sharing rule is more favourable to men for relatively low real expenditure levels. This implies that elderly men are able to attract a relatively higher share of private good equivalents, with the obvious consequence that they are less likely to be labeled as poor (and vice versa for women). However, given the increase in real expenditures over time, female and male shares are converging to each other. Next, Table 4 shows that the traditional approach (only) slightly overestimates the poverty rates among widows and widowers when compared to the collective approach. The explanation is that, as we have indicated before, the (average) scale economies of living in a couple according to the (estimated) collective model are slightly below the scale economies associated with the modified OECD equivalence scale.

We conclude from our above results that, although traditional and collective poverty rates are very similar for widows and widowers, they differ rather markedly when applied to spouses in elderly couples. This is due to the fact that traditional poverty rates completely ignore the (unequal) intra-household allocation of resources.

\subsection{Economic consequences of widow(er)hood}

Another important policy issue is that on the economic consequences of becoming a widow(er). This issue has been widely studied in the literature (see, for example, Holden, Burkhauser and Feaster, 1988, Weir, Willis and Sevak, 2004, and McGarry and Schoeni, 2005). In what follows we try to shed some new light on this issue by using our collective consumption model. A few caveats must be considered before proceeding with a discussion of the results. Firstly, we focus on material well-being. In other words, we only look at the material consequences (more specifically the impact on the expenditures on private good equivalents) of becoming a widow(er) and do not take into account the emotional impact of this event. As such, statements as better or worse off refer to material well-being and do not refer to some bereavement process after becoming a widow(er). Secondly, the figures we show are based on a time series of cross-sections. Consequently, we are not able to analyse the impact of widow(er)hood on an individual-specific basis.

Results are summarized in Table 5. The table shows, for individuals in elderly couples, average minimum expenditures needed when living alone to reach the same

\footnotetext{
${ }^{7}$ See Slesnick (1993), Meyer and Sullivan (2003), Charles et al. (2006) and Hurd and Rohwedder (2006) for a discussion on whether one should focus on consumption or income to measure individual well-being.
} 
indifference curve as when living in a couple (see the numerator of equation (2.10)). These expenditures are calculated for the four different quartiles of the distribution of total household expenditures from the couple's subsample. The table further shows the corresponding average indifference scales for the same groups of households (see equation (2.10)). For widows and widowers we only report the observed household expenditures (the corresponding indifference scales equal 1 by definition).

Let us first focus on the average indifference scales. It is clear from the table that average indifference scales strongly depend on total household expenditures (both within a given time period and across time via increased real expenditures). This is not too surprising given the (economically and statistically) significant impact of real total expenditures on the sharing rule. For example, women in couples that are situated in the first expenditure quartile need 49 per cent of the couple's expenditure level to be equally well off as a widow as when living in a couple. Men in elderly couples situated in the same quartile need about 81 per cent of the couple's total expenditures. The pattern is reversed when we consider couples in the fourth expenditure quartile: women would need on average about 82 per cent of the couple's resources to reach the same indifference curve as a widow, while men only would need about 50 per cent. The results for couples in the second and third expenditure quartiles have an analogous intuition.

Finally, with panel data at hand, we would be able to compare individual indifference scales with the actual percentage of the couple's total expenditures that is available for an individual after becoming a widow(er), which would summarize the material impact of this event. In our data, however, the observed widows (widowers) belong to different cohorts than the women (men) who are living in couples. Still, it does seem useful to interpret the results in Table 5 while maintaining the assumption that widow(er)s are comparable to individuals in couples who are situated in the same expenditure quartile. For a given expenditure quartile and time period, the material impact of becoming a widow(er) then corresponds to the difference between, on the one hand, the actually observed expenditures of widow(er)s (HEX in Table 5) and, on the other hand, the minimally required expenditures of individuals in couples to be materially equally well off when living as a single (in casu a widow(er)) (MEX in Table 5). Under the stated comparability assumption, Table 5 suggests that women in the first and second expenditure quartiles (on average) are materially better off when living as a widow than when living in a couple: for each time period, the corresponding HEX figures exceed the MEX figures. The opposite conclusion holds for women in higher expenditure quartiles, who thus seem to experience a drop in material well-being after becoming a widow. Generally, we observe a reverse pattern for men. Interestingly (and evidently), these results fall in line with our previous findings suggesting the prevalence of economies of scale in households, and a sharing rule that is more beneficial to women in high expenditure couples than in low expenditure couples. 


\section{Conclusion}

We applied the collective consumption model of Browning, Chiappori and Lewbel (2006) to analyse economic well-being and poverty among the elderly. This model is particularly useful in this context because it starts from individual preferences, while accounting for a consumption technology that captures the economies of scale of living in a couple and a sharing rule that governs the intra-household allocation of resources. We applied the model to a time series of consumption expenditure surveys describing the consumption pattern of Dutch elderly households between 1978 and 2004. By combining data from widow(er)s and couples, we are able to identify individual preferences, the consumption technology and the sharing rule. Our empirical results indicate substantial economies of scale associated with living in a couple, and a wife's share that is increasing in the couple's real expenditures.

We have next calculated poverty rates by starting from our estimation results for the collective consumption model. In contrast to traditional poverty rates, which are based on equivalent expenditures or incomes, these collective poverty rates explicitly take into account the unequal intra-household distribution of resources. Collective poverty rates of widows and widowers turn out to be (only) slightly lower than traditional ones that are based on the modified OECD equivalence scale, which reflects that the economies of scale of living in elderly couples are slightly below those incorporated in the OECD scale. More importantly, traditional poverty rates seem to heavily underestimate poverty among women in elderly couples; this is particularly the case for the earlier time periods of the analysis. At the same time, poverty among men in elderly couples is severly overestimated by traditional poverty rates. This result can be explained by the fact that the female's share of the household's resources is increasing in the couple's real expenditures. In the earlier time periods, the household's resources were rather unequally divided among spouses, in that men in elderly couples were allocated a higher share than women. The increase in real expenditures over time induced a more equal sharing of resources, and thus a relatively lower poverty rate among women in elderly couples.

Finally, we analysed the economic impact of the death of a spouse. Based on crosssectional evidence, our results indicate a rather substantial drop in material well-being following the husband's death for women in high expenditure couples. On the other hand, women who are living in low expenditure couples seem to need less than the actually observed expenditures of widows to be materially equally well off when living as a single. The opposite conclusions hold for men. After becoming a widower, high (low) expenditure men are generally materially better (worse) off than when living in a couple. These results (in different directions for men and women) can be explained by the economies of scale of living in a couple, in combination with a sharing rule that is favourable to women in high expenditure couples. 


\section{Appendix}

Table A1 about here.

Table A2 about here.

Table A3 about here.

\section{References}

[1] Banks, J., R. Blundell and A. Lewbel (1997), "Quadratic Engel curves and consumer demand", Review of Economics and Statistics, 79, 527-539.

[2] Becker, G. (1965), "A theory of the allocation of time", Economic Journal, 75, 493-517.

[3] Blundell, R., P.-A. Chiappori and C. Meghir (2005), "Collective labor supply with children", Journal of Political Economy 113, 1277-1306.

[4] Blundell, R. and J.-M. Robin (1999), "Estimation in large and disaggregated demand systems: an estimator for conditionally linear systems", Journal of Applied Econometrics, 14, 209-232.

[5] Bourguignon F., M. Browning and P.-A. Chiappori (2006), "Efficient intrahousehold allocations and distribution factors: implications and identification", CAM working paper, 2006-02, Centre for Applied Microeconometrics, University of Copenhagen.

[6] Browning, M., F. Bourguignon, P.-A. Chiappori and V. Lechene (1994), "Income and outcomes: a structural model of intrahousehold allocation", Journal of Political Economy, 102, 1067-1096.

[7] Browning, M. and P.-A. Chiappori (1998), "Efficient intra-household allocations: a general characterization and empirical tests", Econometrica, 66, 1241-1278.

[8] Browning, M., P.-A. Chiappori and A. Lewbel (2006), "Estimating consumption economies of scale, adult equivalence scales, and household bargaining power", Boston College Working Paper, WP588, Department of Economics, Boston College.

[9] Browning, M. and C. Meghir (1991), "The effects of male and female labor supply on commodity demands", Econometrica, 59, 925-951. 
[10] Charles, K., S. Danziger, L. Pounder and R. Schoeni (2006), "Consumption, income, and well-being among the mature population", working paper, National Poverty Center, University of Michigan.

[11] Cherchye, L., B. De Rock and F. Vermeulen (2007), "The collective model of household consumption: a nonparametric characterization", Econometrica, 75, 553-574.

[12] Cherchye, L. and F. Vermeulen (2006), "Nonparametric analysis of household labor supply: goodness-of-fit and power of the unitary and the collective model", Review of Economics and Statistics, forthcoming.

[13] Chiappori, P.-A. (1988), "Rational household labor supply", Econometrica, 56, 63-89.

[14] Chiappori, P.-A. (1992), "Collective labor supply and welfare", Journal of Political Economy, 100, 437-467.

[15] Coder, J., L. Rainwater and T. Smeeding (1989), "Inequality among children and elderly in ten modern nations: the United States in an international context", American Economic Review, 79, 320-324.

[16] Deaton, A. and J. Muellbauer (1980), "An almost ideal demand system", American Economic Review, 70, 312-336.

[17] Deaton, A. and C. Paxson (1998), "Measuring poverty among the elderly" in D. Wise (ed.), Inquiries in the Economics of Aging, Chicago, Chicago University Press, 169-204.

[18] Engelhardt, G. and J. Gruber (2004), "Social security and the evolution of elderly poverty", NBER Working Paper, WP 10466, National Bureau of Economic Research.

[19] Fortin, B. and G. Lacroix (1997), "A test of the unitary and collective models of household labour supply", Economic Journal, 107, 933-955.

[20] Holden, K., R. Burkhauser and D. Feaster (1988), "The timing of falls into poverty after retirement and widowhood", Demography, 25, 405-414.

[21] Hurd, M. (1990), "Research on the elderly: economic status, retirement, and consumption and saving", Journal of Economic Literature, 28, 565-637.

[22] Hurd, M. and S. Rohwedder (2006), "Economic well-being at older ages: incomeand consumption-based poverty measures in the HRS", NBER Working Paper, WP 12680, National Bureau of Economic Research. 
[23] Johnson, D. and T. Smeeding (2000), "Who are the poor elderly? An examination using alternative poverty measures", Center for Retirement Research Working Paper, 2000-14, Boston College.

[24] Lewbel, A. (2003a), "Calculating compensation in cases of wrongful death", Journal of Econometrics, 113, 115-128.

[25] Lewbel, A. (2003b), "Equivalence scales based on collective household models" in C. Dagum and G. Ferrari (eds.), Household Behavior, Equivalence Scales, Welfare and Poverty, New York, Physica Verlag, 1-9.

[26] Lewbel, A. and K. Pendakur (2006), "Equivalence scales. Entry for the New Palgrave Dictionary of Economics, 2nd Edition", mimeo, Department of Economics, Boston College.

[27] Lundberg, S., R. Pollak and T. Wales (1997), "Do husbands and wives pool their resources? Evidence from the UK child benefit", Journal of Human Resources, 32, 463-480.

[28] McGarry, K. and R. Schoeni (2005), "Widow(er) poverty and out-of-pocket medical expenditures near the end of the life", Journal of Gerontology, 60, 160-168.

[29] Meyer, B. and J. Sullivan (2003), "Measuring the well-being of the poor using income and consumption", Journal of Human Resources, 38, 1180-1220.

[30] Slesnick, D. (1993), "Gaining ground: poverty in the postwar United States", Journal of Political Economy, 101, 1-38.

[31] Smeeding, T. and D. Sullivan (1998), "Generations and the distribution of economic well-being: a cross-national view", American Economic Review, 88, 254-258.

[32] Vermeulen, F. (2002), "Collective household models: principles and main results", Journal of Economic Surveys, 16, 533-564.

[33] Vrooman, C., A. Soede, H.-J. Dirven and R. Trimp (2005), Armoedemonitor 2005 (Poverty Monitor 2005), The Hague, Social and Cultural Planning Office of the Netherlands.

[34] Weir, D., R. Willis and P. Sevak (2004), "The economic consequences of a husband's death: evidence from the HRS and AHEAD", Social Security Bulletin, 65, 31-44.

[35] Zaidi, A., M. Makovec, M. Fuchs, B. Lipszyc, O. Lelkes, M. Rummel, B. Marin and K. de Vos (2006), "Poverty of elderly people in EU25", Report, European Centre for Social Welfare Policy and Research. 
Table 1: Total expenditure and own price elasticities

\begin{tabular}{lcccc}
\hline Widows & Exp. elasticity & Std. error & Price elasticity & Std. error \\
\hline Food & 0.42 & 0.10 & -0.62 & 0.39 \\
Vices & 0.92 & 0.46 & -3.03 & 1.77 \\
Clothing & 1.72 & 0.15 & -0.74 & 0.39 \\
Housing & 1.20 & 0.06 & -0.75 & 0.16 \\
Transport & 1.19 & 0.29 & -0.29 & 0.43 \\
Energy & 0.55 & 0.09 & -0.41 & 0.11 \\
\hline Widowers & Exp. elasticity & Std. error & Price elasticity & Std. error \\
\hline Food & 0.80 & 0.18 & -0.30 & 0.68 \\
Vices & 0.35 & 0.53 & -1.02 & 1.78 \\
Clothing & 1.27 & 0.37 & -0.82 & 1.03 \\
Housing & 1.08 & 0.10 & -0.37 & 0.40 \\
Transport & 1.59 & 0.32 & -0.50 & 0.38 \\
Energy & 0.90 & 0.18 & -0.39 & 0.21 \\
\hline
\end{tabular}

Table 2: Sharing rule parameters

\begin{tabular}{lcc}
\hline & Estimate & Std. error \\
\hline Constant & -6.413 & 2.015 \\
Real expenditures & 1.378 & 0.428 \\
Education difference & 0.187 & 4.176 \\
\hline
\end{tabular}

Table 3: Consumption technology parameters

\begin{tabular}{lcccc}
\hline & Estimate (a) & Std. error & Estimate (A) & Std. error \\
\hline Food & 4.539 & 1.849 & 0.995 & 0.013 \\
Vices & 1.880 & 1.694 & 0.934 & 0.070 \\
Clothing & 3.530 & 1.593 & 0.986 & 0.090 \\
Housing & -0.756 & 0.686 & 0.660 & 0.041 \\
Transport & -0.155 & 3.228 & 0.731 & 0.158 \\
Energy & -1.706 & 1.084 & 0.577 & 0.031 \\
\hline
\end{tabular}

Table 4: Poor individuals

\begin{tabular}{|c|c|c|c|c|c|}
\hline & 1978-1982 & 1983-1987 & 1988-1992 & 1993-1997 & 1998-2004 \\
\hline \multicolumn{6}{|l|}{ Women in couples } \\
\hline Collective approach & 50.98 & 25.68 & 17.50 & 8.22 & 1.92 \\
\hline Traditional approach & 33.22 & 8.65 & 5.00 & 0.86 & 0.00 \\
\hline \multicolumn{6}{|l|}{ Widows } \\
\hline Collective approach & 29.21 & 4.02 & 1.40 & 0.82 & 0.00 \\
\hline Traditional approach & 31.18 & 4.89 & 1.87 & 0.82 & 0.00 \\
\hline \multicolumn{6}{|l|}{ Men in couples } \\
\hline Collective approach & 8.63 & 0.14 & 0.00 & 0.00 & 0.00 \\
\hline Traditional approach & 33.22 & 8.65 & 5.00 & 0.86 & 0.00 \\
\hline \multicolumn{6}{|l|}{ Widowers } \\
\hline Collective approach & 33.86 & 15.31 & 1.23 & 0.00 & 0.00 \\
\hline Traditional approach & 37.01 & 16.33 & 2.47 & 1.33 & 0.00 \\
\hline
\end{tabular}


Table 5: Economic well-being and indifference scales

\begin{tabular}{|c|c|c|c|c|c|c|c|}
\hline & & 1978-1982 & 1983-1987 & 1988-1992 & 1993-1997 & 1998-2004 & Average IS \\
\hline \multicolumn{8}{|l|}{ Women in couples } \\
\hline \multirow[t]{2}{*}{ First expenditure quartile } & MEX & 1743.81 & 2388.40 & 2755.94 & 3368.52 & 4339.18 & \\
\hline & IS & 0.44 & 0.47 & 0.49 & 0.51 & 0.54 & 0.49 \\
\hline \multirow[t]{2}{*}{ Second expenditure quartile } & MEX & 2657.13 & 3834.71 & 4469.91 & 5486.04 & 6748.05 & \\
\hline & IS & 0.53 & 0.58 & 0.61 & 0.64 & 0.66 & 0.60 \\
\hline \multirow[t]{2}{*}{ Third expenditure quartile } & MEX & 3638.89 & 5724.34 & 6240.64 & 7359.40 & 9158.69 & \\
\hline & IS & 0.60 & 0.69 & 0.71 & 0.72 & 0.73 & 0.69 \\
\hline \multirow[t]{2}{*}{ Fourth expenditure quartile } & MEX & 6197.70 & 9514.32 & 10040.68 & 11486.81 & 15298.04 & \\
\hline & IS & 0.75 & 0.83 & 0.83 & 0.84 & 0.88 & 0.82 \\
\hline \multicolumn{8}{|l|}{ Widows } \\
\hline First expenditure quartile & HEX & 2662.54 & 3545.61 & 3859.74 & 4734.21 & 5935.90 & \\
\hline Second expenditure quartile & HEX & 3423.21 & 4569.66 & 4809.17 & 6036.00 & 7376.59 & \\
\hline Third expenditure quartile & HEX & 4278.98 & 5722.61 & 5758.32 & 7138.59 & 8681.20 & \\
\hline Fourth expenditure quartile & HEX & 6022.82 & 8161.63 & 7813.73 & 10075.30 & 11366.31 & \\
\hline \multicolumn{8}{|l|}{ Men in couples } \\
\hline \multirow[t]{2}{*}{ First expenditure quartile } & MEX & 3283.24 & 4211.88 & 4429.01 & 5150.02 & 6104.67 & \\
\hline & IS & 0.84 & 0.84 & 0.80 & 0.80 & 0.77 & 0.81 \\
\hline \multirow[t]{2}{*}{ Second expenditure quartile } & MEX & 3800.03 & 4778.93 & 5009.51 & 5873.44 & 6817.75 & \\
\hline & IS & 0.76 & 0.73 & 0.69 & 0.69 & 0.67 & 0.71 \\
\hline \multirow[t]{2}{*}{ Third expenditure quartile } & MEX & 4145.11 & 5199.71 & 5346.27 & 6213.78 & 7407.07 & \\
\hline & IS & 0.69 & 0.63 & 0.61 & 0.61 & 0.60 & 0.63 \\
\hline \multirow[t]{2}{*}{ Fourth expenditure quartile } & MEX & 4537.20 & 5514.21 & 5728.90 & 6611.54 & 7909.21 & \\
\hline & IS & 0.56 & 0.50 & 0.49 & 0.50 & 0.47 & 0.50 \\
\hline \multicolumn{8}{|l|}{ Widowers } \\
\hline First expenditure quartile & HEX & 2366.40 & 3072.86 & 3911.31 & 4250.91 & 5658.31 & \\
\hline Second expenditure quartile & HEX & 3254.37 & 4254.16 & 5078.15 & 5805.07 & 7447.57 & \\
\hline Third expenditure quartile & HEX & 4214.78 & 5339.93 & 5916.73 & 7297.47 & 9130.07 & \\
\hline Fourth expenditure quartile & HEX & 6215.66 & 8768.66 & 7845.84 & 10650.08 & 12020.17 & \\
\hline
\end{tabular}


Table A1: Summary statistics

\begin{tabular}{lcccccc}
\hline & Couples & \multicolumn{3}{c}{ Widows } & \multicolumn{3}{c}{ Widowers } \\
\hline Budget shares & Mean & Std. dev. & Mean & Std. dev. & Mean & Std. dev. \\
\hline Food & 0.30 & 0.09 & 0.24 & 0.08 & 0.22 & 0.08 \\
Vices & 0.04 & 0.05 & 0.02 & 0.03 & 0.06 & 0.06 \\
Clothing & 0.11 & 0.06 & 0.11 & 0.07 & 0.05 & 0.04 \\
Housing & 0.39 & 0.11 & 0.47 & 0.11 & 0.48 & 0.11 \\
Transport & 0.05 & 0.04 & 0.03 & 0.03 & 0.04 & 0.05 \\
Energy & 0.12 & 0.04 & 0.14 & 0.05 & 0.15 & 0.06 \\
Total expenditures* & 11893.14 & & 8287.06 & 2608.12 & 8150.28 & 3206.80 \\
Total income* & 24142.30 & & 14830.39 & 5409.65 & 17585.18 & 8284.87 \\
Second. education** & 0.46 & & 0.34 & & 0.42 & \\
Higher education** & 0.18 & & 0.07 & & 0.10 & \\
Car owner & 0.67 & & 0.20 & & 0.48 & \\
Home owner & 0.42 & & 0.26 & & 0.28 & \\
1978-1982 & 0.20 & & 0.26 & & 0.28 & \\
1983-1987 & 0.25 & & 0.25 & & 0.21 & \\
1988-1992 & 0.19 & & 0.15 & & 0.17 & \\
1993-1997 & 0.19 & & 0.17 & & 0.17 & \\
1998-2004 & 0.17 & & 0.17 & & 0.17 & \\
\hline Prices & Mean & Range & Mean & Range & Mean & Range \\
\hline Price of food & 89.39 & 39.80 & 88.47 & 39.80 & 88.63 & 39.80 \\
Price of vices & 75.84 & 77.43 & 74.18 & 77.43 & 74.14 & 77.43 \\
Price of clothing & 99.28 & 26.03 & 98.90 & 26.03 & 98.64 & 26.03 \\
Price of housing & 69.31 & 73.51 & 67.66 & 73.51 & 67.74 & 73.51 \\
Price of transport & 77.99 & 60.17 & 77.28 & 60.17 & 77.85 & 60.17 \\
Price of energy & 80.56 & 89.52 & 79.57 & 89.52 & 80.01 & 89.52 \\
\hline * Values in 2004 euro & & & & & & \\
** Refers to husbands in couples & & & & & \\
\hline & & & & & & \\
& & & & & & \\
\end{tabular}


Table A2: Widow's demand system parameter estimates

\begin{tabular}{|c|c|c|c|c|c|c|c|c|c|c|c|c|}
\hline & Food & & Vices & & Clothing & & Housing & & Transport & & Energy & \\
\hline & Param. & Std. error & Param. & Std. error & Param. & Std. error & Param. & Std. error & Param. & Std. error & Param. & Std. error \\
\hline Constant & 67.80 & 1.04 & 8.44 & 0.45 & -14.44 & 0.94 & 0.81 & 1.10 & -0.93 & 0.45 & -64.20 & $\star *$ \\
\hline Ageclass & -1.20 & 0.02 & -0.16 & 0.01 & -0.45 & 0.02 & 1.51 & 0.03 & -0.10 & 0.01 & 0.31 & ** \\
\hline Higher educ. & 0.36 & 0.08 & 0.39 & 0.04 & -0.80 & 0.07 & -0.58 & 0.11 & 1.06 & 0.04 & -0.70 & $\star *$ \\
\hline Car owner & -1.05 & 0.06 & 0.39 & 0.03 & -1.43 & 0.06 & -0.53 & 0.09 & 3.02 & 0.03 & -0.64 & ** \\
\hline Home owner & 0.02 & 0.07 & -0.02 & 0.03 & -3.05 & 0.07 & 3.06 & 0.09 & -0.69 & 0.02 & 0.42 & $* *$ \\
\hline 1983-1987 & -1.62 & 0.09 & 0.09 & 0.04 & -1.80 & 0.08 & 2.36 & 0.11 & -0.12 & 0.03 & 0.77 & ** \\
\hline 1988-1992 & -1.71 & 0.15 & 0.15 & 0.07 & -1.77 & 0.13 & 4.35 & 0.19 & -0.08 & 0.05 & -1.47 & $* *$ \\
\hline $1993-1997$ & -2.18 & 0.24 & 0.83 & 0.12 & -1.22 & 0.21 & 4.67 & 0.31 & -0.37 & 0.09 & -2.61 & ** \\
\hline 1998-2004 & -0.46 & 0.30 & 0.77 & 0.13 & 0.13 & 0.26 & 2.02 & 0.39 & -0.02 & 0.10 & -3.53 & $\star *$ \\
\hline Real exp. & -13.31 & 0.74 & -4.75 & 0.32 & 17.88 & 0.68 & 16.87 & 0.70 & 2.91 & 0.35 & -22.05 & ** \\
\hline Real exp. sq. & 0.05 & 0.15 & 1.00 & 0.07 & -1.93 & 0.14 & -1.55 & 0.13 & -0.50 & 0.07 & 2.44 & $\star \star$ \\
\hline Price food & 1.04 & 0.89 & -1.75 & $\star \star$ & 6.06 & $\star *$ & 1.78 & $\star *$ & -1.12 & $\star \star$ & -6.91 & ** \\
\hline Price vices & -1.75 & 0.36 & -4.13 & 0.32 & 3.67 & $\star *$ & 2.16 & ** & 0.19 & $\star *$ & -0.82 & $\star *$ \\
\hline Price clothing & 6.06 & 0.58 & 3.67 & 0.26 & -0.90 & 0.54 & -13.72 & $\star \star$ & -0.03 & ** & 3.55 & ** \\
\hline Price energy & -6.02 & $\star *$ & -0.14 & $\star *$ & 4.93 & $\star *$ & -0.65 & $* *$ & 0.20 & $\star \star$ & 1.67 & ** \\
\hline Residual & 10.74 & 0.23 & 1.87 & 0.09 & -7.04 & 0.21 & -5.30 & 0.30 & -0.61 & 0.08 & -0.49 & ** \\
\hline
\end{tabular}

* All parameter estimates and standard errors are multiplied by 100.

** Parameters obtained by means of theoretical restrictions. 
Table A3: Widower's demand system parameter estimates

\begin{tabular}{|c|c|c|c|c|c|c|c|c|c|c|c|c|}
\hline & Food & & Vices & & Clothing & & Housing & & Transport & & Energy & \\
\hline & Param. & Std. error & Param. & Std. error & Param. & Std. error & Param. & Std. error & Param. & Std. error & Param. & Std. error \\
\hline Constant & 40.72 & 1.61 & 22.71 & 1.28 & 8.26 & 0.99 & 48.79 & 1.99 & -12.45 & 0.96 & -112.91 & ** \\
\hline Ageclass & -0.40 & 0.05 & -0.76 & 0.04 & -0.54 & 0.03 & 0.95 & 0.06 & -0.21 & 0.03 & 0.78 & $* *$ \\
\hline Higher educ. & -2.74 & 0.18 & 1.36 & 0.15 & 0.28 & 0.10 & 3.06 & 0.24 & 0.47 & 0.11 & -3.11 & $* *$ \\
\hline Car owner & -0.61 & 0.10 & -0.82 & 0.08 & -1.45 & 0.05 & -0.46 & 0.13 & 4.88 & 0.06 & -1.91 & ** \\
\hline Home owner & -1.80 & 0.16 & 1.11 & 0.12 & -1.27 & 0.09 & 4.07 & 0.20 & -2.51 & 0.09 & -0.16 & $\star \star$ \\
\hline 1983-1987 & -0.60 & 0.19 & 0.88 & 0.13 & -0.53 & 0.09 & 0.66 & 0.22 & -0.19 & 0.09 & -0.84 & $\star *$ \\
\hline 1988-1992 & 0.71 & 0.31 & 3.30 & 0.27 & 0.98 & 0.18 & 0.44 & 0.41 & -2.21 & 0.13 & -4.40 & $\star \star$ \\
\hline 1993-1997 & 1.08 & 0.49 & 3.52 & 0.46 & 1.34 & 0.30 & -2.88 & 0.66 & -0.68 & 0.20 & -4.30 & $\star \star$ \\
\hline 1998-2004 & 1.91 & 0.60 & 5.40 & 0.52 & 1.26 & 0.33 & -5.16 & 0.77 & 0.05 & 0.24 & -5.68 & $\star \star$ \\
\hline Real exp. & -8.37 & 0.98 & -8.19 & 0.74 & -0.23 & 0.64 & -7.78 & 1.04 & 11.17 & 0.54 & 10.01 & $\star *$ \\
\hline Real exp. sq. & 0.83 & 0.18 & 0.88 & 0.14 & 0.40 & 0.13 & 2.50 & 0.19 & -1.49 & 0.10 & -3.76 & ** \\
\hline Price food & 12.16 & 1.54 & 2.10 & $\star *$ & -0.27 & $\star \star$ & -7.96 & $\star \star$ & -1.38 & $\star *$ & -6.19 & $\star \star$ \\
\hline Price vices & 2.10 & 1.06 & -2.23 & 1.18 & 6.28 & $\star \star$ & -8.63 & ** & -2.73 & $\star \star$ & 2.96 & $\star \star$ \\
\hline Price clothing & -0.27 & 0.79 & 6.28 & 0.62 & 0.73 & 0.58 & -10.84 & $\star \star$ & 3.29 & ** & -1.18 & ** \\
\hline Price energy & -4.65 & $\star \star$ & 5.20 & $\star \star$ & 0.80 & $\star *$ & -4.00 & $\star \star$ & -3.28 & $\star *$ & 5.92 & $\star \star$ \\
\hline Residual & 7.11 & 0.44 & 7.84 & 0.33 & -0.75 & 0.23 & -6.69 & 0.55 & -6.04 & 0.25 & -3.01 & $\star *$ \\
\hline
\end{tabular}

* All parameter estimates and standard errors are multiplied by 100

** Parameters obtained by means of theoretical restrictions. 